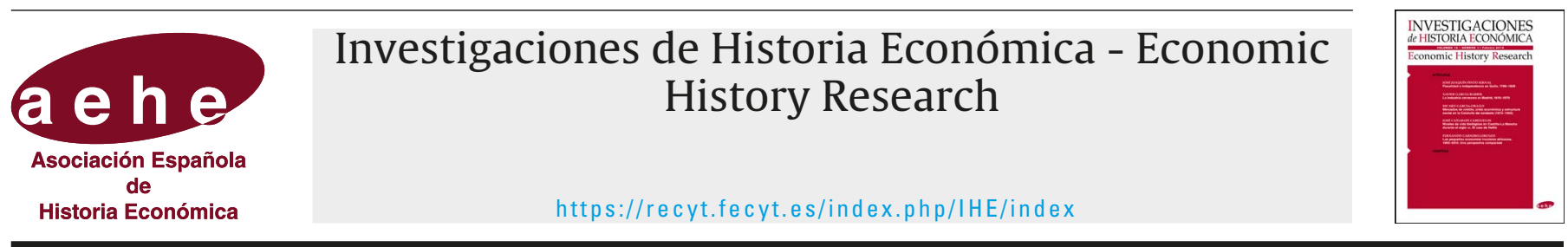

Artículo

\title{
El artesanado sedero y las fluctuaciones del mercado laboral en la Valencia preindustrial (1479-1836)
}

\author{
Daniel Muñoz Navarro* (D) \\ Universitat de València
}

\section{Ricardo Franch Benavent ${ }^{* *}$ \\ Universitat de València}

\section{INFORMACIÓN DEL ARTÍCULO}

\section{Historia del artículo:}

Recibido: 17 de marzo de 2020

Aceptado: 12 de junio de 2020

On-line: 4 de agosto de 2020

\section{Códigos JEL:}

N33

N6

N90

N93

Palabras clave:

Gremios

Trabajo

Seda

Valencia

\section{R E S U M E N}

Este estudio aborda el análisis del gremio de velluters de Valencia durante toda su existencia, desde su creación en 1479 hasta el decreto de abolición de estas corporaciones en 1836. Se trata del gremio que controlaba la elaboración de tejidos de seda, la principal actividad industrial de dicha ciudad durante toda la Edad Moderna. La excepcionalidad de las fuentes archivísticas de esta institución nos permite analizar las fluctuaciones de su mercado laboral, tanto a través de la reconstrucción de la evolución del número de maestros como del análisis socioprofesional de los 9439 candidatos examinados para acceder a dicha condición. A través de este estudio de caso pretendemos contribuir al debate sobre el retorno gremial, reivindicando la necesidad de análisis contextualizados a la hora de ponderar el papel jugado por los gremios durante el Antiguo Régimen y su grado de flexibilidad y apertura.

(C) 2020 Asociación Española de Historia Económica

\section{The silk weavers' craft guild and the fluctuations of the labour market in pre-industrial Valencia (1479-1836)}

\section{A B S T R A C T}

This article focuses on the analysis of the silk weavers' craft guild (gremio de velluters) in Valencia throughout its existence, from its creation in 1479 until the abolition decree of these corporations in 1836. This guild controlled the main industrial activity of this city during the entire early modern period. The exceptional nature of the archival sources of this institution allows us to observe the fluctuations of its labour market, through the reconstruction of the evolution of the number of masters and the socio-professional analysis of the 9,439 candidates examined to access the master's degree. Through this case study, the aim is to contribute to the debate of "the return of guild", claiming the importance of contextualized analyses, in order to consider the role played by craft guilds during the Ancien Regime and its grade of flexibility and openness.

\section{Guilds}

Keywords:

Labour

Silk

Valencia

\footnotetext{
* Autor de correspondencia. Correo electrónico: daniel.munoz@uv.es

** Correo electrónico: ricardo.franch@uv.es
} 


\section{Introducción}

La reciente literatura sobre el retorno gremial ha permitido reconsiderar el papel jugado por las corporaciones de oficios en las economías de Antiguo Régimen, superando la visión tradicional, que definía estas instituciones como elementos de atraso. Este proceso de renovación historiográfica defiende la flexibilidad de los gremios y su contribución al proceso de desarrollo económico en la Europa preindustrial. Pese a ello, todavía queda un largo camino por recorrer a la hora de ponderar el papel jugado por esta institución global, debido a la enorme heterogeneidad que entraña el sistema gremial en Europa y fuera de ella. Las tendencias generales dibujadas a partir de esta nueva mirada no siempre reflejan el carácter dinámico y fluctuante de estas corporaciones, por lo que resulta necesario enriquecer el mosaico con nuevos casos de estudio.

Una parte importante del debate ha pivotado sobre el mayor o menor grado de apertura de los gremios, pero este enfoque resulta insuficiente hoy en día, ya que ¿cómo podemos explicar que una misma corporación sea abierta o cerrada según el momento en que la analicemos? A fin de enriquecer la discusión, este estudio aborda un análisis micro de un único gremio durante toda su existencia, desde su creación en 1479 hasta la disolución del mismo como corporación de oficio en 1836. Nos referimos al gremio de velluters de Valencia, que aglutinaba a la elite artesanal de la principal actividad industrial de esta ciudad durante toda la Edad Moderna. Esta investigación pretende demostrar que esta corporación fue ambas cosas, y que su grado de apertura o cierre varió en función del contexto histórico en el que operaba y de la respuesta adoptada por sus miembros a los desafíos que se planteaban.

\section{La literatura del retorno gremial desde la perspectiva española}

A día de hoy, existe un cierto consenso entre los historiadores del trabajo a la hora de afirmar que los gremios no fueron barreras infranqueables para el crecimiento económico, lo que supone un importante giro con respecto a los planteamientos clásicos. Esta nueva perspectiva, obviamente no aceptada de manera omnímoda (Ogilvie, 2008, 2019), se fundamenta en el papel central de estas instituciones en la organización del trabajo preindustrial, siendo su presencia especialmente densa en las regiones más urbanizadas. Pese a las restricciones de las ordenanzas gremiales, destaca el hecho de que estas normas ni fueron inmutables ni su aplicación fue estricta, por lo que necesariamente debemos aproximarnos a la realidad del mercado laboral artesanal. La literatura del retorno gremial relanzó las investigaciones sobre este tipo de instituciones, reorientando su estudio hacia un enfoque más dinámico y comparativo, y dando pie a un debate historiográfico que aún continúa abierto. En él han jugado un papel central los planteamientos de Epstein (1998), quien partiendo de un enfoque teórico marcó el camino a toda una generación de historiadores que en las últimas décadas han desarrollado un buen número de publicaciones empíricas. La flexibilidad y la capacidad de adaptación de los gremios a contextos cambiantes se sitúan en la base de este nuevo enfoque, aunque el debate fue más allá al tratar de mesurar el impacto económico de los gremios a partir de diversos estudios de caso (Epstein y Prak, 2008). El predominio que los gremios tuvieron en las manufacturas urbanas en la Europa preindustrial y el impacto positivo que ejercieron en las economías de Antiguo Régimen (estructurando el mercado laboral y la transferencia del conocimiento técnico, garantizando unos estándares de calidad y/o reduciendo los costes de producción) son un hecho que podemos considerar contrastado por la historiografía. No obstante, no debemos olvidar las restricciones impuestas a través de sus ordenanzas, que limitaban en gran medida el trabajo femenino o imponían tasas que dificultaban la movilidad laboral, en favor de los hijos de maestros.

Esta mirada renovada ha tenido eco en buena parte de Europa (Caracausi et al., 2018; Mocarelli y Ongaro, 2019; Prak y Wallis, 2020), aunque su desarrollo ha sido especialmente intenso en el caso de los gremios en los Países Bajos, donde se ha reivindicado el papel dinamizador de estas instituciones, mucho más allá de su condición monopolística (Stabel, 2004; De Munck, 2011). El interés de los historiadores se ha focalizado en el análisis de los sistemas de aprendizaje y la transmisión del conocimiento técnico, permitiendo situar las corporaciones gremiales en un contexto social mucho más amplio que el inicialmente previsto por Epstein (De Munck, 2007, pp. 8-9). En relación con la introducción de innovaciones, se ha incidido en el lento pero constante proceso de adaptación de los gremios al contexto a través de la introducción de pequeños cambios (productivos o de tipo organizativo), con el fin de adaptar la producción a la demanda, siempre dentro de su marco institucional, político y también natural o físico (Trivellato, 2008, p. 228).

Siguiendo esta estela, Lucassen et al. (2009, p. 9) afirmaban que la pregunta correcta no es "whether guilds were important or unimportant, backward or innovative, but rather under what circumstances they could play such a role». La conexión entre gremios e innovaciones tecnológicas en las ciudades europeas del Antiguo Régimen ha sido objeto de debate, evidenciando la complejidad del tema desde una perspectiva comparada y la amplia gama de variables (de carácter exógeno y endógeno) que interactuaban en este proceso de renovación. El denominador común en esta discusión es la insuficiencia de los planteamientos teóricos y la necesidad de ir más allá de los gremios, enmarcándolos en su contexto (Davis y De Munck, 2014).

En los últimos años, esta visión renovada en torno a los gremios se ha situado en posturas cada vez más optimistas, que defienden la idea general de que «openness was much more common than closure, especially in larger cities» (Prak et al., 2020, p. 1). No obstante, esta visión contrasta con la heterogénea realidad de los gremios españoles. Pese al creciente interés historiográfico en torno a los gremios en la Europa preindustrial, el peso de las corporaciones españolas en este debate ha sido escaso hasta el momento ${ }^{1}$. La visión ordenancista que tradicionalmente había dominado los estudios sobre gremios en España comenzó a matizarse -siguiendo la estela de este debate europeo-, reivindicando el carácter cambiante de estas corporaciones, la reducción de costes que favoreció, su conexión con la protoindustria y la necesidad de estudiar caso por caso la presunta oposición frontal de los gremios españoles a las innovaciones tecnológicas (López y Nieto, 1996; Casado, 2004).

Una de las preguntas principales es cuál fue el grado de apertura de los gremios españoles y su contribución a la formación de un mercado laboral flexible. Las investigaciones de

\footnotetext{
1 Puede verse una sintética perspectiva historiográfica en Nieto (2013, p. 98).
} 
José Nieto y Juan Carlos Zofío (2015) han permitido conocer en profundidad la evolución de los gremios de Madrid durante la Edad Moderna. No obstante, la singularidad de este caso de estudio nos obliga a plantearnos hasta qué punto la flexibilidad y modernidad de estas instituciones puede ser extrapolada a otros espacios peninsulares, tanto castellanos como aragoneses (Hernández y González, 2015). Si bien el caso madrileño apunta a tasas de parentesco entre los nuevos maestros inferiores al $20 \%$ y un elevado grado de movilidad geográfica durante todo el siglo xviII (Nieto y Zofío, 2015, pp. 54-58), otros estudios aportan datos menos optimistas. El análisis sobre el origen socioprofesional de los nuevos aprendices y maestros del gremio de veleros de Barcelona entre 1770 y 1834 plantea una tendencia creciente al cierre social de la corporación (con tasas de parentesco próximas al $50 \%$ ) y un escaso grado de movilidad, ya que casi todos los nuevos maestros eran catalanes (el 64\% provenía de la ciudad de Barcelona). Una mayor dispersión geográfica se aprecia en el caso de los aprendices, aunque cabe destacar que solo el $12,49 \%$ de ellos llegaron a alcanzar la maestría (Solà y Yamamichi, 2015, pp. 85-89). Por lo que a Valencia se refiere, la panorámica es aún menos favorable ante la creciente endogamia y la progresiva proletarización del artesanado sedero durante el siglo xviII (Franch et al., 2016).

\section{El gremio de velluters de Valencia. Fuentes y metodolo- gía de análisis}

El objetivo inicialmente planteado de llevar a cabo un análisis micro de la evolución del artesanado sedero valenciano durante la Edad Moderna se sustenta en la excepcional riqueza del archivo del Colegio del Arte Mayor de la Seda de Valencia y la continuidad de la mayoría de sus series documentales, que abarcan desde 1479 hasta finales del siglo xIx. De este modo, el estudio sistemático de algunas de ellas (las que reflejan las fluctuaciones laborales), nos ha permitido disponer de estadísticas que abarcan los 357 años de existencia de esta corporación gremial.

La sección documental más útil para el conocimiento de los efectivos globales de la corporación son los libros de clavarios, en los que se recogían las cuentas anuales de ingresos y gastos. Disponemos de 323 libros correspondientes al periodo comprendido entre 1479 y 1856, en cada uno de los cuales se incluye una relación nominal de los maestros existentes, ordenados alfabéticamente por su nombre. Al parecer, el oficio los registraba exhaustivamente, ya que su finalidad era el control del pago de la cuota anual que debían satisfacer los maestros, indicando con frecuencia si alguno no la abonaba por hallarse ausente, por su condición de pobreza o por defunción. Esta última circunstancia no siempre quedaba anotada, limitándose a eliminar al fallecido en la relación del año siguiente ${ }^{2}$. Además, en los libros de clavarios se anotaban también las tasas pagadas por los maestros cuando realizaban el examen de acceso a dicha condición o, en el caso de los oficiales, se matriculaban en la corporación. La información sobre los primeros precisaba nombre, procedencia geográfica, modalidad de producción, fecha del examen y las tasas que debía abonar el candidato. A partir de 1687, tras la obtención del privilegio de colegio, se otorgó

\footnotetext{
2 En cuanto a los oficiales, se recurría a un sistema similar para controlar el abono de su cuota anual, aunque esta información dejó de registrarse a partir del ejercicio 1686-87, por lo que la serie está incompleta.
}

una mayor trascendencia al proceso, registrándose el examen de maestría en un libro específicamente destinado a tal efecto. Desde mediados del siglo xvII, además, se impuso el pago de una tacha sobre el número de telares. Por tanto, para el periodo 1700-1721 disponemos de libros de tacha, duplicándose la información disponible, aunque a partir de 1748 la Junta General de Comercio prohibió esta imposición y se volvió al sistema de abono de capítulos, reflejados en libros de capítulos.

Sirviéndonos de estos fondos documentales, hemos centrado la investigación fundamentalmente en dos variables conectadas entre sí: la evolución anual del número de maestros, y el acceso de nuevos miembros a dicha condición a través del examen correspondiente. La menor calidad y continuidad de la información relativa a las categorías inferiores (aprendices y oficiales) nos ha inducido a centrar el análisis en la élite artesanal. Al constituir el rango superior de la jerarquía laboral del oficio, la evolución de sus efectivos y de la procedencia social y geográfica de los nuevos maestros refleja perfectamente la capacidad de atracción que tenía el sector sobre el mercado laboral de la ciudad de Valencia.

Para conocer la evolución del número de maestros existentes, se ha procedido a la contabilización de los registrados en los 209 volúmenes de los libros de clavarios correspondientes al periodo 1479-1721; los 29 libros de la tacha del periodo 172148, y los 57 libros de capítulos existentes de los años 1748$1834^{3}$. Es decir, se han consultado un total de 295 libros relativos a un periodo de 355 años. Cuando se especificaba que alguno de los maestros registrados había fallecido, se ha omitido su contabilización, por lo que la cifra obtenida corresponde al número neto de maestros existentes en cada ejercicio. Asimismo, con el fin de simplificar la presentación de la información, se ha asignado el resultado obtenido al año natural en el que finalizaba el mandato de los cargos directivos.

Con respecto a los exámenes de maestría, se ha elaborado una base de datos de los 9439 registrados mediante la consulta de los 214 libros de clavarios del periodo 1479-1726 y los 7 libros de exámenes relativos a los años $1726-1836^{4}$, y se ha finalizado la investigación en este año, ya que el decreto emitido el 2 de diciembre de 1836 transformó completamente la naturaleza de los gremios, al dejar de ser una entidad obligatoria. Las tasas pagadas por los derechos de examen variaban en función de los candidatos, diferenciándose entre los hijos de los maestros, los oficiales de procedencia valenciana, los forasteros nacidos en otros territorios de la monarquía y los de origen extranjero. Esta diferenciación es clave para conocer la composición social y geográfica de los nuevos maestros, así como para calibrar las barreras de acceso y el grado de discriminación impuesto por la corporación.

La exhaustividad y continuidad de la información obtenida sobre la élite artesanal sedera, que controló la principal actividad económica de una de las mayores ciudades de la monarquía hispánica (y de la Europa mediterránea) durante todo el periodo moderno, nos permite extraer conclusiones fundamentadas y

\footnotetext{
${ }^{3}$ Archivo del Colegio del Arte Mayor de la Seda de Valencia (ACAMSV). Sig. 2.1/libros 1 a 209 (libros de clavarios); sig. 2.4.1/ libros 11 a 40 (libros de tacha) y 41 a 98 (libros de capítulos).

${ }^{4}$ ACAMSV. Sig. 2.1/libros 1 a 214 (libros de clavarios); sig. 2.2.1/libros 2 a 8 (libros de exámenes de maestro). Los registros de examen corresponden a todos los que superaron la prueba, excluyendo a los dos únicos candidatos (sobre un total de 9439) que la suspendieron en 1717 y 1738 (Franch, 2014, p. 45).
} 
datos fehacientes con los que contribuir al debate sobre la flexibilidad y apertura de las corporaciones gremiales del Antiguo Régimen, enriqueciéndolo a partir de nuevos casos de estudio.

\section{La evolución de la élite sedera valenciana en el contexto de las fluctuaciones del mercado laboral (1479-1836)}

Como se ha indicado anteriormente, los gremios no eran entidades aisladas que actuaban exclusivamente en función de su dinámica interna. Su actividad productiva se hallaba intensamente condicionada por el entorno urbano en el que se ubicaba la corporación y por el contexto económico, social y político en el que se llevaba a cabo. Estos factores exógenos a la corporación gremial podían resultar cruciales tanto para favorecer el dinamismo del sector como para dificultar su desarrollo y condicionar la crisis de la actividad manufacturera. La respuesta que adoptaba la corporación artesanal ante dichas condiciones tenía también un peso fundamental en su evolución posterior, aunque muchas veces se hallaba tan influenciada por aquel contexto que difícilmente se puede diferenciar entre lo que podría considerarse como los factores exógenos o endógenos.

El despegue inicial de la industria sedera valenciana estuvo claramente determinado por factores de naturaleza exógena. En el momento de fundación del gremio de velluters, a finales del siglo xv, Valencia era la segunda ciudad de mayor tamaño de la península ibérica, con una población intramuros que oscilaba entre los 40000 y 50000 habitantes 5 . Además, estaba ubicada en el centro de una fértil llanura litoral, con una elevada densidad de población y una agricultura muy dinámica que generaba abundantes excedentes comercializables, ejerciendo la función de mercado urbano para su extenso hinterland. A ello debemos unir la hegemonía que ejercía sobre el conjunto del territorio valenciano, fruto de su condición de capital política del reino. Asimismo, su excelente posición geográfica la convirtió en una auténtica encrucijada en la que confluían las rutas comerciales más importantes del Mediterráneo occidental, por lo que era el mercado principal del litoral mediterráneo ibérico. Las intensas oportunidades de negocio que todo ello generaba explican la capacidad de atracción que tenía a comienzos de la Edad Moderna y la afluencia de inmigrantes de la más diversa cualificación y procedencia, lo que le confería un marcado carácter cosmopolita.

El colectivo de inmigrantes que ejerció una mayor influencia fue el de origen italiano, tanto por sus dimensiones como por la elevada cualificación laboral de sus miembros (Igual, 1998). Entre ellos, sin duda, el grupo más numeroso era el de los genoveses, cuyos comerciantes trataban de adquirir en Valencia las materias primas para abastecer su industria textil urbana. La demanda genovesa estimuló la difusión del cultivo de la morera tanto en el sur de Italia como en el este de la península ibérica, por lo que el Reino de Valencia se convirtió en la principal zona productora de fibra de seda de España ya a mediados del siglo xvi (Franch, 1999). Pero, además, los genoveses también trasladaron a Valencia parte de su negocio manufacturero, tratando de abaratar costes o beneficiarse de un mercado laboral menos saturado. De esta forma, contribuyeron

\footnotetext{
${ }^{5}$ Se trata de la segunda urbe de la península ibérica hacia 1500 de las 48 ciudades analizadas en el estudio de J. De Vries (1987, pp. 355-357), solo por detrás de Granada.
}

decisivamente a la renovación de la industria sedera, transfiriendo una nueva tecnología productiva y un nuevo modelo organizativo, basado en el Arte della seta genovés, difundiendo las técnicas utilizadas en el norte de Italia para la elaboración de tejidos lujosos de seda y favoreciendo la creación del gremio de velluters en 1479 (Navarro, 1999). La intensa incorporación de artesanos genoveses vino acompañada de la llegada de trabajadores castellanos, andaluces, aragoneses, catalanes, etc., poniendo de manifiesto el dinamismo del mercado laboral sedero durante esta fase inicial. De este modo, el gremio se convirtió rápidamente en la corporación artesanal más numerosa e influyente de la ciudad.

La evolución numérica de los maestros del gremio de velluters constituye uno de los mejores indicadores de la trayectoria de la industria sedera valenciana. El análisis de las series documentales anteriormente descritas permite conocer su entidad año tras año, entre 1479 y 1836 (figura 1). Por su parte, la tabla 1 refleja el promedio anual de maestros por décadas y el porcentaje de variación con respecto al periodo anterior. A través de estos datos podemos diferenciar varias etapas que evidencian las fluctuaciones del mercado laboral sedero valenciano a lo largo del periodo estudiado, las cuales trataremos de explicar según el contexto histórico, conectado con la evolución del gremio. La primera etapa se corresponde con el periodo inicial de despegue y dinamismo, que abarca la centuria comprendida entre 1479 y 1579. Tras la creación del gremio de velluters en 1479 , la cifra de maestros creció de forma muy moderada, oscilando desde más o menos los 200 efectivos hasta aproximadamente 1500. La introducción de nuevas técnicas textiles por parte de los comerciantes y artesanos de origen italiano fue un proceso complejo que requería la creación de los talleres artesanales y la formación de mano de obra contratada. Además, la ciudad sufrió en dichos años diversos contagios epidémicos y crisis de subsistencias que dificultaron la expansión inicial del sector.

El proceso de expansión continuó a principios del siglo xvI, intensificándose claramente en la década de 1510 y dando lugar a que la cifra de maestros se duplicara en los años previos a la revuelta agermanada. El gremio de velluters se convirtió entonces en el oficio más importante de la ciudad de Valencia, lo que explica el protagonismo que tuvieron sus miembros en la dirección de la protesta artesanal. Las causas de esta se han atribuido tradicionalmente a la crisis que estaba experimentando este sector social (García Cárcel, 1975), pero, en el caso de los sederos, su descontento obedecía en mayor medida a su marginación del gobierno municipal y a la oposición a los gravámenes fiscales exigidos sobre sus manufacturas. La información obtenida recientemente desmiente que la represión posterior provocase una crisis definitiva de la sedería valenciana a lo largo de siglo xvI, como se ha indicado tradicionalmente. El retroceso numérico fue solo coyuntural y el crecimiento se reanudó a mediados de la década de 1520 . De ahí que el promedio anual del número de maestros de dicho decenio se incremente incluso un $2,92 \%$ con respecto al periodo anterior. La tendencia incluso se intensificó con posterioridad y se prolongó hasta la década de 1570 , cuando los maestros triplicaban prácticamente los registrados a principios de la centuria. Esta evolución está corroborada por las fuentes fiscales que gravaban la elaboración de tejidos de seda o las exportaciones a Castilla (Franch et al., 2019, p. 108), que ponen de manifiesto un crecimiento productivo incluso superior al de los efectivos de la corporación artesanal, lo que puede indicar que estos disponían de unas mejores condiciones de producción. 


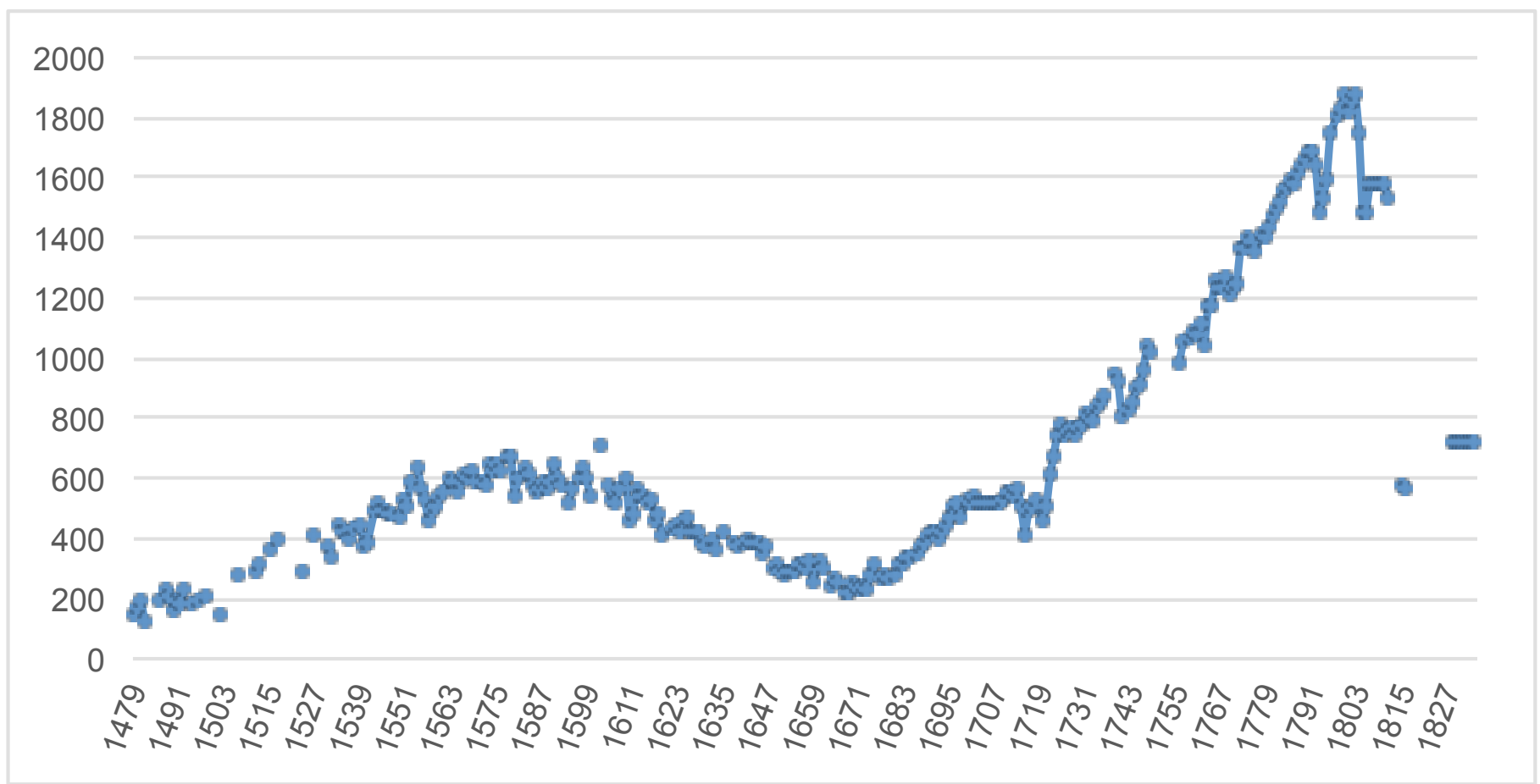

Figura 1. Evolución del número de maestros tejedores de seda de Valencia (1479-1836).

Fuente: elaboración propia. ACAMSV. Sig. 2.1/1-209 y sig. 2.4.1/ 11-98.

Pero, a medida que avanzaba el siglo xvi, los factores exógenos que habían favorecido la expansión comenzaron a transformarse. Significativamente, el carácter dinámico y cosmopolita de la ciudad de Valencia tendió a reducirse, en consonancia con su progresivo desplazamiento de las grandes rutas del comercio internacional ante la creciente hegemonía del tráfico atlántico. La finalización de la guerra de Granada facilitó el desarrollo de las ciudades portuarias del sureste peninsular, como Cartagena y Alicante, mejor ubicadas en las rutas que conectaban el Atlántico y el norte de Italia, mermando considerablemente la capacidad de atracción de la ciudad de Valencia. Ciertamente, el retroceso del tráfico marítimo fue compensado con la intensificación de los vínculos con Castilla, pero el producto fundamental que ofrecía el Reino de Valencia en este tráfico era la fibra de seda, destinada a abastecer la industria toledana. Las condiciones sociopolíticas del artesanado valenciano se vieron afectadas por el fracaso de la revuelta de las Germanías, ya que no solo consagró la definitiva marginación de este grupo social en el gobierno local, sino que generó también una notable represión económica que perjudicó especialmente a los miembros del gremio de velluters (García Cárcel, 1975; Pérez García, 2017). Su actividad manufacturera se vio afectada cada vez más por las intensas remesas de fibra de seda hacia Castilla. Pero, además, ante el florecimiento de este comercio terrestre, las Cortes valencianas impusieron un nuevo tributo sobre la seda en 1552 con el fin de financiar la defensa costera. Al generar unos recursos insuficientes, se fue incrementando la tarifa que gravaba el tráfico, lo que estimuló un intenso flujo de contrabando que lastró aún más la competitividad de los tejidos valencianos (Franch, 1999; Muñoz, 2015).

La respuesta que adoptó la corporación artesanal ante el creciente deterioro de las condiciones en las que se desarro- llaba la actividad productiva en la segunda mitad del siglo XVI no hizo más que agravar los problemas que se estaban experimentando. El sustancial incremento de los gravámenes fiscales, derivado de las dificultades económicas, tanto de la monarquía como de las instituciones regnícolas y municipales, provocó que la corporación gremial tratase de defenderse recurriendo a los tribunales. Pero los elevados costes de estos pleitos, unido a la creciente conflictividad judicial contra otros gremios y contra los propios maestros que se negaban a hacer frente a las tachas impuestas por la corporación, intensificaron los problemas financieros. Los registros de la producción manufacturera de finales de la centuria revelan también la existencia de una intensa polarización social entre los artesanos sederos, ya que una pequeña minoría de ellos (junto con algunos comerciantes) controlaba la mayor parte de la actividad. La proletarización experimentada por la mayoría de los maestros se agravaba por la reducción del número de oficiales que se produjo en este periodo, lo que pone de manifiesto que aquellos eran incapaces de contratar a esta mano de obra más cualificada. Asimismo, aunque los registros aludidos revelan un incremento del volumen de la producción realizada, el análisis de su composición permite comprobar una reorientación de la producción en favor de los tejidos más ligeros y baratos (Franch, 1999). Es decir, se había llevado a cabo una reconversión del sector con el fin de adaptar los géneros a la reducción de la capacidad adquisitiva sufrida por la población, sobre todo en Castilla, que constituía el principal mercado consumidor de los tejidos de seda valencianos. Pero el factor endógeno que pudo contribuir en mayor medida a intensificar la crisis que comenzó a sufrir la corporación artesanal a finales de la centuria fue su tentativa de resolver las dificultades financieras internas mediante el incremento de las tasas exigidas para la realización del examen de acceso a la 
condición de maestro. Es decir, la inversión requerida para ejercer el oficio se estaba elevando en un contexto de crisis, lo que, como veremos posteriormente, contribuyó al progresivo cierre del gremio ante el escaso atractivo del sector para la mano de obra no vinculada con las familias que controlaban el sector.

Las dificultades que experimentó la sedería valenciana en el último tercio del siglo xvi se hallan perfectamente reflejadas en la evolución de los maestros sederos, plasmada en la tabla 1. Como puede apreciarse, entre 1580 y 1609 la cifra se estabilizó en algo menos de 600 efectivos. Pero este periodo de estancamiento fue solo la antesala de la intensa crisis que experimentó el sector a partir de la década de 1610, reduciéndose desde entonces la cifra de maestros por lo general a un ritmo decenal superior al $10 \%$. La corporación tocó fondo en la década de 1660, con un promedio de 263 maestros (el año 1667 el número cayó hasta 221, lo que suponía un descenso próximo al 60 \% en el número de efectivos con respecto al comienzo de la centuria). No obstante, la incidencia de esta crisis en Valencia fue inferior a la del principal centro sedero castellano, Toledo, que durante esta fase inició una decadencia prácticamente irreversible (Aranda, 2017). Por el contrario, la sedería valenciana comenzó en el último tercio del siglo xvi una vigorosa recuperación que sentó las bases del periodo de esplendor del siglo xvIII, cuando la ciudad de Valencia alcanzó una hegemonía incontestable sobre este sector en España.

\section{Tabla 1}

Evolución número de maestros tejedores de seda en Valencia (1479-1836)

\begin{tabular}{|c|c|c|}
\hline Décadas & $\begin{array}{l}\text { Promedio anual } \\
\text { maestros }\end{array}$ & $\begin{array}{l}\text { Variación } \% \\
\text { por décadas }\end{array}$ \\
\hline $1479-89$ & 179 & - \\
\hline $1490-99$ & 199 & 11,17 \\
\hline $1500-09$ & 215 & 8,04 \\
\hline 1510-19 & 342 & 59,07 \\
\hline $1520-29$ & 352 & 2,92 \\
\hline $1530-39$ & 412 & 17,05 \\
\hline $1540-49$ & 466 & 13,11 \\
\hline $1550-59$ & 535 & 14,81 \\
\hline $1560-69$ & 586 & 9,53 \\
\hline $1570-79$ & 634 & 8,19 \\
\hline \multicolumn{2}{|c|}{ Dinamismo 1479-1579 } & 15,99 \\
\hline $1580-89$ & 582 & $-8,20$ \\
\hline 1590-99 & 593 & 1,89 \\
\hline $1600-09$ & 578 & $-2,53$ \\
\hline \multicolumn{2}{|c|}{ Estancamiento 1580-1609 } & $-2,95$ \\
\hline $1610-19$ & 501 & $-13,32$ \\
\hline $1620-29$ & 431 & $-13,97$ \\
\hline $1630-39$ & 386 & $-10,44$ \\
\hline
\end{tabular}

\footnotetext{
${ }^{6}$ Estos datos indican la variación porcentual en el promedio de maestros con respecto a la década inmediatamente anterior.
}

\begin{tabular}{|lcc|}
\hline \multicolumn{1}{|c}{ Décadas } & $\begin{array}{c}\text { Promedio anual } \\
\text { maestros }\end{array}$ & $\begin{array}{c}\text { Variación \% } \\
\text { por décadas }^{6}\end{array}$ \\
\hline $1640-49$ & 366 & $-5,18$ \\
\hline $1650-59$ & 297 & $-18,85$ \\
\hline $1660-69$ & 263 & $-11,45$ \\
\hline Crisis 1610-1669 & 262 & $\mathbf{- 1 2 , 2 0}$ \\
\hline $1670-79$ & 346 & $-0,38$ \\
\hline $1680-89$ & 460 & 32,06 \\
\hline $1690-99$ & 522 & 32,95 \\
\hline $1700-09$ & 511 & 13,48 \\
\hline $1710-19$ & & $-2,11$ \\
\hline Recuperación 1670-1719 & 709 & $\mathbf{1 5 , 2 0}$ \\
\hline $1720-29$ & 848 & 38,75 \\
\hline $1730-39$ & 917 & 19,61 \\
\hline $1740-49$ & 1.048 & 8,14 \\
\hline $1750-59$ & 1.181 & 14,29 \\
\hline $1760-69$ & 1.364 & 12,69 \\
\hline $1770-79$ & 1.574 & 15,50 \\
\hline $1780-89$ & 1.692 & 15,40 \\
\hline $1790-99$ & & 7,50 \\
\hline Expansión 1720-1799 & 1.661 & $\mathbf{1 6 , 4 8}$ \\
\hline $1800-09$ & 1.066 & $-1,83$ \\
\hline $1810-19$ & 727 & $-35,82$ \\
\hline $1820-36$ & & $-31,80$ \\
\hline Decadencia 1800-1836 & & $\mathbf{- 2 3 , 1 5}$ \\
\hline
\end{tabular}

Fuente: elaboración propia. ACAMSV. Sig. 2.1/1-209 y sig. 2.4.1/ 11-98.

Las causas de la recuperación aludida se derivaron, en gran medida, de factores exógenos. La intensa transformación agraria del mundo rural valenciano, tras la expulsión de los moriscos, contribuyó a la aparición de explotaciones campesinas excedentarias que orientaban su producción hacia los cultivos comercializables, entre los cuales destacó la morera. En consecuencia, el Reino de Valencia intensificó su hegemonía en la producción de fibra de seda. Este hecho, unido a la grave decadencia de la sedería toledana y las medidas proteccionistas que adoptaron las instituciones valencianas a finales del siglo xvII, sentaron las bases para el inicio de una nueva etapa de expansión. La crisis toledana conllevó una ardua polémica en torno a qué hacer con los abultados excedentes de materia prima (Franch, 2000, 2004). En ese contexto, las instituciones valencianas adoptaron estímulos fiscales para favorecer la producción y exportación de tejidos de seda valencianos hacia Castilla, lo que contribuyó al inicio de una intensa recuperación de la actividad manufacturera a partir de la década de 1670. En esta favorable coyuntura, el gremio de velluters puso en marcha una serie de transformaciones internas, entre las que destaca el esfuerzo por incrementar su consideración social, y obtuvo en 1686 el privilegio que le permitía adoptar la denominación de "arte mayor». La corporación hizo gala también entonces de un intenso dinamismo, disponiendo una reglamentación técnica menos rígida que la existente en los centros castellanos; estimulando la imitación de los 
tejidos labrados que se elaboraban en Francia e Italia, y tratando de facilitar la comercialización de la producción en el mercado cortesano. Todo ello estimuló, de nuevo, el mercado laboral y las oportunidades de negocio, y contribuyó a la intensificación de la corriente migratoria que afluía a Valencia.

Como queda reflejado en la tabla 1 , el retroceso que había experimentado el número de maestros sederos desde principios de la centuria se paralizó en la década de 1670 , creciendo a un ritmo superior al $30 \%$ en las dos décadas siguientes. El estallido de la guerra de Sucesión no paralizó el proceso, que solo se vio afectado por el drástico incremento de la presión fiscal que se impuso al final de la contienda y que se refleja en el balance ligeramente negativo que se produjo en la década de 1710. Sin embargo, fue inmediatamente después de la finalización de la guerra cuando se inició el periodo de esplendor que caracterizó a la sedería valenciana en el siglo xviII. Resulta significativo que el número de maestros se doblase prácticamente entre 1716-1725, creciendo a un ritmo anual del 6,5\%, frente a las tasas de entre el 1 y el $2 \%$ que se alcanzarían habitualmente en el resto de la centuria (Franch et al., 2016, p. 29). A largo de la centuria este crecimiento solo fue ocasionalmente interrumpido por algunas crisis coyunturales. De ahí que el balance global sea tan positivo, ya que se cuadriplicó aproximadamente la entidad de dicho colectivo entre 1715 y 1799 . La cifra anual más alta de toda la serie se registró en este último año, con 1882 efectivos contabilizados, lo que pone de manifiesto la importancia adquirida por el sector en esta centuria de esplendor.

Las causas de este intenso crecimiento fueron, en gran medida, de naturaleza exógena, ya que se derivaron de la política mercantilista adoptada por la monarquía borbónica. Cabría destacar entre ellas la eliminación de las aduanas internas; la racionalización fiscal; la prohibición de la importación de los tejidos asiáticos; el estímulo del consumo de manufacturas autóctonas tanto en el mercado peninsular como, sobre todo, en el colonial, o la prohibición de la exportación de materia prima de seda a partir de 1739 . No obstante, la contrapartida de este intenso proteccionismo fue el reforzamiento de las atribuciones de la corporación gremial, que extendió su jurisdicción al conjunto del reino -lo que dificultó el desarrollo de esta industria fuera de la capital- e impuso la adecuación de su producción a los criterios de calidad de carácter tradicional (Franch, 2000). Amparándose en la necesidad de combatir la deficiente calidad de las manufacturas, se impuso la normativa técnica establecida en las ordenanzas generales de tejidos de seda de 1684, cuyo carácter tradicional había contribuido a la decadencia de la sedería castellana. Cuando la propia monarquía tomó conciencia de que ello dificultaba la adaptación de la producción valenciana a las nuevas corrientes de la moda francesa, el Colegio del Arte Mayor de la Seda de Valencia reaccionó defendiendo sus prerrogativas y los criterios tradicionales de producción de manera beligerante. De ahí que a partir de mediados del siglo xviII las sedas valencianas fuesen desplazadas en el mercado peninsular por tejidos más ligeros y vistosos de origen francés, y que quedaran básicamente relegadas al mercado colonial debido a las ventajas fiscales de que allí disponían y a los gustos más tradicionales de las élites criollas (Franch, 2000; Muñoz, 2017). El crecimiento excesivo de la población gremial generó también desequilibrios internos, cuyos efectos se agu- dizaron en la segunda mitad de la centuria. El control empresarial del sector fue muy intenso, dando lugar al desarrollo de una burguesía sedera muy enriquecida. Sin embargo, ello comportó también una intensa proletarización del artesanado sedero. Si bien el número de maestros crecía con regularidad, la cifra de telares se estabilizó desde mediados de siglo, al igual que la de oficiales registrados, evidenciando la creciente precariedad de las condiciones laborales.

La gravedad que adquirió en Valencia el motín antifrancés de 1793, agudizado por la crisis artesanal que refleja la reducción del número de maestros en dicho año (como puede verse en la figura 1), constituye un buen reflejo de la hostilidad que generaba en el sector la competencia francesa. Pero a las dificultades generadas por su hegemonía en el mercado peninsular se añadieron las surgidas en el colonial como consecuencia de su creciente saturación, agudizada por la afluencia de los tejidos asiáticos tras la creación de la Compañía de Filipinas en 1785. En estas condiciones, la actividad resultaba cada vez menos atractiva para los artesanos ajenos al gremio, y más teniendo en cuenta la discriminación laboral derivada de las elevadas tasas de examen que se exigían, como veremos posteriormente. De ahí la inversión de la tendencia secular ascendente del número de maestros que se aprecia ya en la primera década del siglo xix.

Con unos 100000 habitantes, según el censo de Floridablanca, Valencia era entonces la ciudad más populosa del litoral mediterráneo español y seguía siendo la segunda de España (Fortea, 2009, pp. 90-92), aunque había perdido su carácter cosmopolita. Se trataba, además, de una ciudad industrial, ya que, según diversos testimonios, la mitad de su población trabajaba, directa o indirectamente, en la industria de la seda (Franch, 2000). Sin embargo, los desequilibrios que afectaban al sector se intensificaron a finales de la centuria debido a la paralización del comercio colonial como consecuencia de las guerras revolucionarias, la emancipación posterior de los países americanos, la intensificación de la competencia de los tejidos de seda franceses y el triunfo definitivo de los géneros de algodón. La caída del número de maestros que se produjo tras la finalización de la guerra de la Independencia, hasta llegar a niveles próximos a los existentes a finales del siglo xvi, revela tanto la intensidad de la crisis como la supervivencia del sector, que sufriría una lenta agonía el resto de la centuria. En este contexto, la orientación cada vez más liberal de la política económica de la monarquía mermó las prerrogativas y la capacidad de influencia de las corporaciones gremiales, lo que causó su abolición en 1836.

\section{Exámenes de maestría y procedencia social y geográfica de la élite artesanal}

Junto a la evolución del número de maestros matriculados, las fuentes archivísticas del gremio de velluters nos informan sobre la procedencia social y geográfica de los 9439 examinados para acceder a la condición de maestría durante el periodo comprendido entre 1479 y 1836, lo que nos ayuda a comprender el mercado laboral sedero de la ciudad de Valencia. Uno de los elementos clave a tener en cuenta son las tasas de examen exigidas a los aspirantes, las cuales fueron incrementándose en el periodo analizado, como ya se ha venido apuntando (tabla 2). 


\section{Tabla 2}

Evolución de los derechos de examen de maestría del gremio de velluters de Valencia, en libras valencianas y en jornales diarios $^{7}$

\begin{tabular}{clrrc} 
Año & \multicolumn{1}{c}{ Tipo } & De la tierra & Forasteros & Extranjeros \\
\multirow{2}{*}{1479} & Libras & 2,5 & 5 & 5 \\
& Jornales & 12,5 & 25 & 25 \\
\hline \multirow{2}{*}{1495} & Libras & 2,5 & 5 & 7,5 \\
& Jornales & 12,5 & 25 & 37,5 \\
\hline \multirow{2}{*}{1599} & Libras & 5 & 10 & 15 \\
& Jornales & 17 & 33 & 50 \\
\hline \multirow{2}{*}{1602} & Libras & 6 & 12 & 15 \\
& Jornales & 20 & 40 & 50 \\
\hline \multirow{2}{*}{1604} & Libras & 12 & 18 & 24 \\
& Jornales & 40 & 60 & 80 \\
\hline \multirow{2}{*}{1631} & Libras & 16 & 24 & 32 \\
& Jornales & 53 & 80 & 107 \\
\hline \multirow{2}{*}{1675} & Libras & 24 & 36 & 48 \\
& Jornales & 80 & 120 & 160 \\
\hline \multirow{2}{*}{1687} & Libras & 36 & 54 & 72 \\
& Jornales & 120 & 180 & 240 \\
\hline \multirow{2}{*}{1714} & Libras & 54 & 81 & 108 \\
\cline { 2 - 5 } & Jornales & 180 & 270 & 360 \\
\hline \multirow{2}{*}{$*$} & & & & \\
\hline
\end{tabular}

Fuente: elaboración propia. ACAMSV. Sig. 2.1/1-209.

Inicialmente, los derechos exigidos no constituían un grave obstáculo para los candidatos no vinculados familiarmente con la corporación, ya que en las ordenanzas de 1479 se establecieron unas tasas relativamente moderadas. Teniendo en cuenta la importancia que los artesanos de origen extranjero habían tenido en la creación de la corporación, se diferenciaron dos categorías básicas: los de origen valenciano y los que procedían de otros territorios, entre los que se incluían tanto los que pertenecían a la monarquía hispánica como a los súbditos de otras monarquías. Ambos colectivos debían estar representados equitativamente en los cargos directivos de la corporación, pero las tasas de acceso al gremio que se exigían a los segundos doblaban las estipuladas para los primeros. Asimismo, se disponía que los hijos de los maestros estuvieran exentos del abono de las tasas. Existía, por tanto, una discriminación en favor de los hijos de maestros, pero la inversión que se requería para el resto de candidatos equivalía solo al salario de 12,5 (los valencianos) o 25 (los no valencianos) días de trabajo.

\footnotetext{
${ }^{7}$ El jornal diario se calcula en base al salario de los peones valencianos de la construcción. Para el siglo xvI, este se mantuvo en 4 sueldos (valor empleado para calcular la cantidad equivalente en jornales para las tasas impuestas en 1479 y 1495), se elevó a 6 sueldos a partir de 1600 y se estabilizó hasta finales del siglo xvIII. Este último valor es el que hemos empleado para las equivalencias en jornales a partir de 1599 (Hamilton, 1983, pp. 411-421; Palop, 1977, pp. 275-276).
}

En 1495, el gremio pretendió incrementar la discriminación, doblando la tasa a los candidatos valencianos y distinguiendo, además, entre los que procedían de otros territorios de la monarquía hispánica (forasteros), a los que se les doblaba la tasa anterior, y a los extranjeros, a los que se les quería exigir 15 libras, equivalentes a 75 días de trabajo. No obstante, la ciudad de Valencia se opuso al incremento planeado para los dos primeros colectivos y solo admitió la diferenciación del tercero, pero reduciendo la tasa a la mitad de lo inicialmente proyectado por la corporación. Esta intervención constituyó una buena muestra de la acción moderadora que el poder político podía ejercer con respecto a las pretensiones exclusivistas de las corporaciones gremiales. En todo caso, las tasas establecidas en 1495 se mantuvieron inalteradas hasta finales del siglo xvI, contribuyendo a favorecer la afluencia de artesanos de diversa procedencia y, consiguientemente, a conferir el carácter abierto y dinámico que caracterizó al gremio en dicha centuria.

Las figuras 2 y 3 , que a su vez contienen los datos de la tabla 3 , reflejan la evolución numérica y porcentual de cada uno de los colectivos que se diferencian en los 9439 exámenes de maestría realizados entre 1479 y 1836 . La presencia de candidatos de origen extranjero fue muy intensa en las dos primeras décadas de funcionamiento de la corporación y, aunque se redujo después, siguió siendo considerable hasta la década de 1540. Su retroceso fue compensado, en parte, por el incremento de los candidatos forasteros, lo que puso de manifiesto el papel que ejercía la ciudad de Valencia en la difusión de las nuevas técnicas textiles procedentes del norte de Italia hacia los restantes centros manufactureros de la monarquía hispánica. Ambos colectivos representaron más de la tercera parte de los nuevos maestros examinados hasta el último tercio del siglo xvI, y se situaron para el periodo $1480-1579$ en el 35,75\%. Un porcentaje algo superior representaban los candidatos de origen valenciano, mientras que los hijos de los maestros solo a partir de la década de 1530 comenzaron a superar el $10 \%$ de los examinados, y alcanzaron para el periodo 1480-1579 el $20,22 \%$.

No cabe duda, por tanto, que el gremio de velluters conoció en los cien primeros años de funcionamiento su etapa de mayor apertura y atracción de mano de obra cualificada de procedencia lejana, sin que las tasas de examen representasen un factor limitante para ello. Pero a partir de mediados de siglo, la capacidad de atracción del mercado laboral sedero se fue reduciendo, sobre todo para los extranjeros, dando lugar a que en el periodo de estancamiento manufacturero comprendido entre 1580 y 1609 su proporción bajase hasta el 3,07\%. La presencia de candidatos forasteros solo se debilitó ligeramente, oscilando habitualmente entre el $20-30 \%$ de los exámenes realizados, aunque en la primera década del siglo xviI bajó hasta el 12,16\%. Los de origen valenciano siguieron representando en torno al $40 \%$, mientras que los hijos de los maestros fueron incrementando su importancia, pero en el periodo 1580-1609 solo alcanzaron un porcentaje del $34,16 \%$.

\footnotetext{
${ }^{8}$ Durante el periodo de dinamismo, especialmente hasta la década de 1520 , adquirieron cierta relevancia el porcentaje de "otros» (2,24\%), que se corresponde fundamentalmente con segundos exámenes de maestros sederos que querían diversificar su producción en varias tipologías textiles.
} 


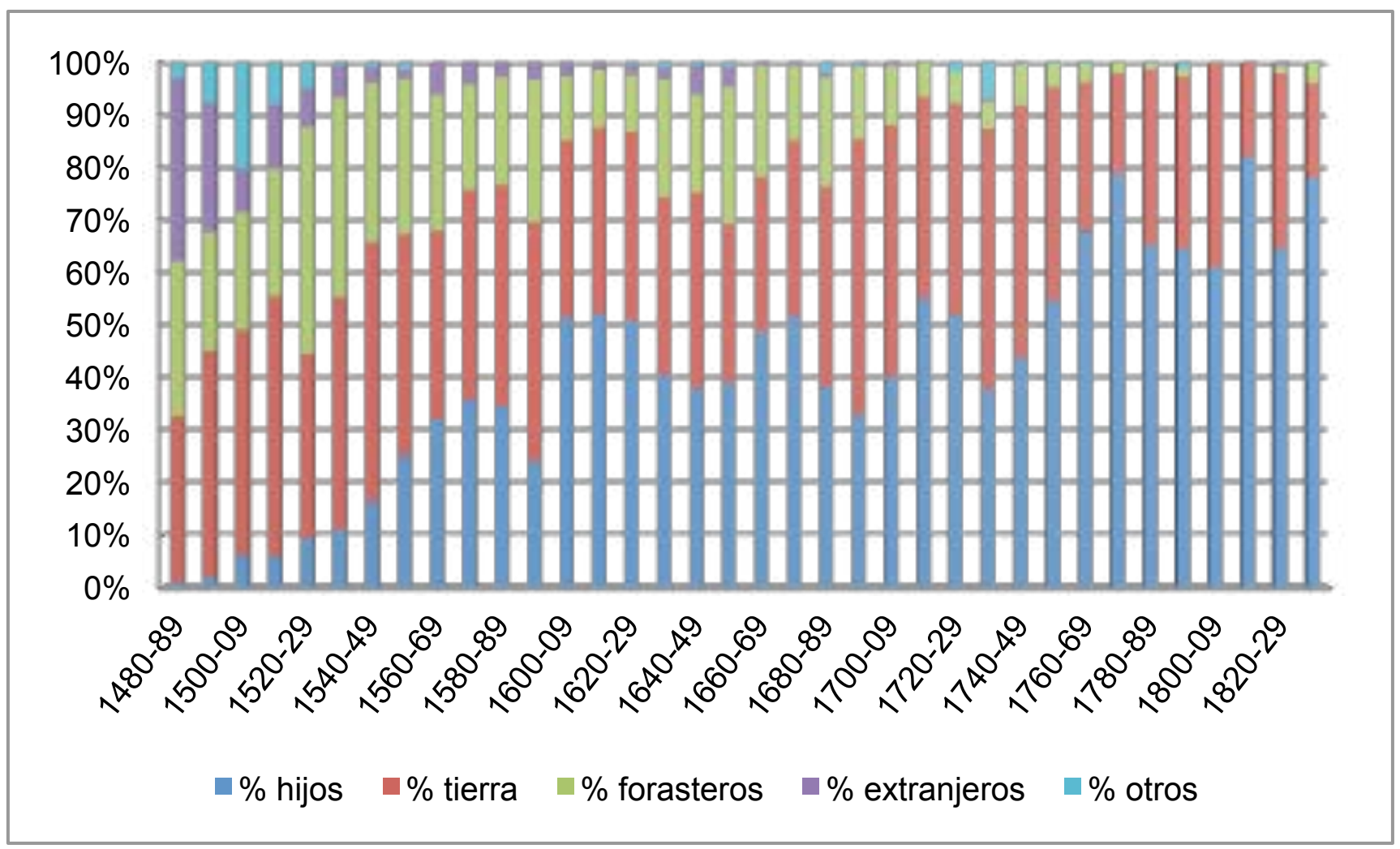

Figura 2. Evolución porcentual de los exámenes de maestría del gremio de velluters de Valencia, según su condición socioprofesional (1480-1836). Fuente: elaboración propia. ACAMSV. Sig. 2.1/1-214 y sig. 2.2.1/2-8.

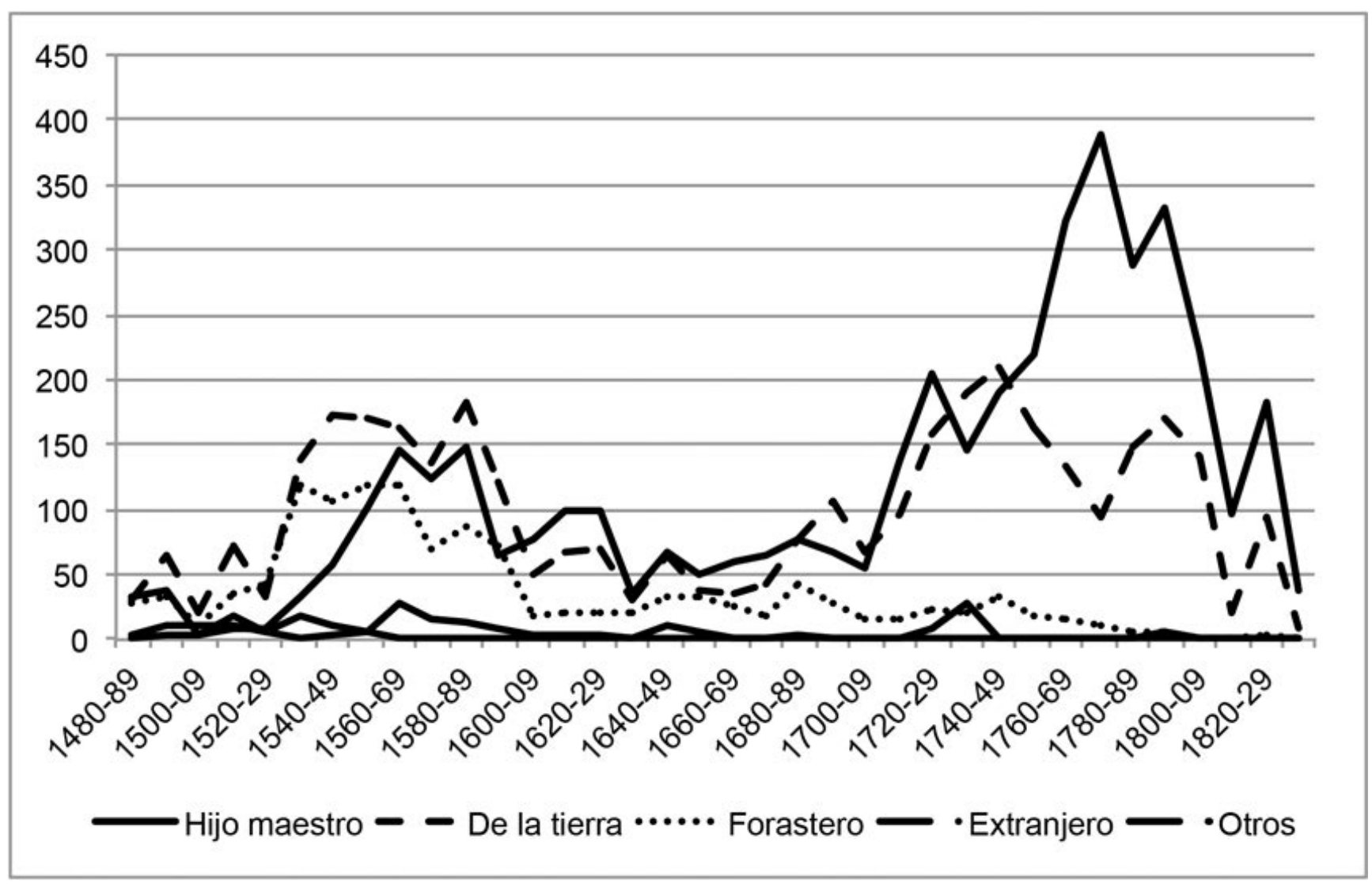

Figura 3. Evolución decenal del número de maestros sederos examinados, según su condición socioprofesional (1479-1836). Fuente: elaboración propia. ACAMSV. Sig. 2.1/1-214 y sig. 2.2.1/2-8. 
Tabla 3

Exámenes de maestría del gremio de velluters de Valencia, según origen socioprofesional (1480-1836)

\begin{tabular}{|c|c|c|c|c|c|c|c|c|c|c|c|}
\hline \multirow{2}{*}{ Décadas } & \multicolumn{2}{|c|}{ Hijos de maestro } & \multicolumn{2}{|c|}{ De la tierra } & \multicolumn{2}{|c|}{ Forasteros } & \multicolumn{2}{|c|}{ Extranjeros } & \multicolumn{2}{|c|}{ Otros $^{9}$} & \multirow{2}{*}{ Total } \\
\hline & no & $\%$ & no & $\%$ & no & $\%$ & no & $\%$ & no & $\%$ & \\
\hline $1480-89$ & 1 & 1,05 & 30 & 31,58 & 28 & 29,47 & 33 & 34,74 & 3 & 3,16 & 95 \\
\hline 1490-99 & 3 & 1,99 & 65 & 43,05 & 34 & 22,52 & 37 & 24,50 & 12 & 7,95 & 151 \\
\hline 1500-09 & 3 & 6,12 & 21 & 42,86 & 11 & 22,45 & 4 & 8,16 & 10 & 20,41 & 49 \\
\hline 1510-19 & 9 & 6,08 & 73 & 49,32 & 36 & 24,32 & 18 & 12,16 & 12 & 8,11 & 148 \\
\hline $1520-29$ & 9 & 9,28 & 34 & 35,05 & 42 & 43,30 & 7 & 7,22 & 5 & 5,15 & 97 \\
\hline $1530-39$ & 34 & 10,93 & 138 & 44,37 & 118 & 37,94 & 19 & 6,11 & 2 & 0,64 & 311 \\
\hline $1540-49$ & 58 & 16,43 & 174 & 49,29 & 107 & 30,31 & 10 & 2,83 & 4 & 1,13 & 353 \\
\hline 1550-59 & 102 & 25,12 & 171 & 42,12 & 120 & 29,56 & 7 & 1,72 & 6 & 1,48 & 406 \\
\hline $1560-69$ & 145 & 31,94 & 163 & 35,90 & 118 & 25,99 & 28 & 6,17 & 0 & 0,00 & 454 \\
\hline $1570-79$ & 123 & 35,76 & 137 & 39,83 & 69 & 20,06 & 15 & 4,36 & 0 & 0,00 & 344 \\
\hline Dinamismo 1480-1579 & 487 & 20,22 & 1.006 & 41,78 & 683 & 28,36 & 178 & 7,39 & 54 & 2,24 & 2.408 \\
\hline $1580-89$ & 149 & 34,49 & 182 & 42,13 & 88 & 20,37 & 13 & 3,01 & 0 & 0,00 & 432 \\
\hline $1590-99$ & 64 & 24,06 & 121 & 45,49 & 72 & 27,07 & 9 & 3,38 & 0 & 0,00 & 266 \\
\hline $1600-09$ & 76 & 51,35 & 50 & 33,78 & 18 & 12,16 & 4 & 2,70 & 0 & 0,00 & 148 \\
\hline Estancamiento 1580-1609 & 289 & 34,16 & 353 & 41,73 & 178 & 21,04 & 26 & 3,07 & $\mathbf{0}$ & $\mathbf{0 , 0 0}$ & 846 \\
\hline 1610-19 & 99 & 52,11 & 67 & 35,26 & 21 & 11,05 & 3 & 1,58 & 0 & 0,00 & 190 \\
\hline $1620-29$ & 99 & 50,77 & 70 & 35,90 & 21 & 10,77 & 4 & 2,05 & 1 & 0,51 & 195 \\
\hline $1630-39$ & 36 & 40,45 & 30 & 33,71 & 20 & 22,47 & 2 & 2,25 & 1 & 1,12 & 89 \\
\hline $1640-49$ & 67 & 37,85 & 66 & 37,29 & 33 & 18,64 & 10 & 5,65 & 1 & 0,56 & 177 \\
\hline $1650-59$ & 49 & 38,89 & 38 & 30,16 & 33 & 26,19 & 5 & 3,97 & 1 & 0,79 & 126 \\
\hline $1660-69$ & 60 & 48,78 & 36 & 29,27 & 26 & 21,14 & 1 & 0,81 & 0 & 0,00 & 123 \\
\hline Crisis 1610-1669 & 410 & 45,56 & 307 & 34,11 & 154 & 17,11 & 25 & 2,78 & 4 & 0,44 & 900 \\
\hline $1670-79$ & 66 & 51,56 & 43 & 33,59 & 18 & 14,06 & 1 & 0,78 & 0 & 0,00 & 128 \\
\hline $1680-89$ & 77 & 38,12 & 77 & 38,12 & 42 & 20,79 & 2 & 0,99 & 4 & 1,98 & 202 \\
\hline $1690-99$ & 67 & 32,84 & 107 & 52,45 & 28 & 13,73 & 1 & 0,49 & 1 & 0,49 & 204 \\
\hline 1700-09 & 56 & 40,00 & 67 & 47,86 & 16 & 11,43 & 1 & 0,71 & 0 & 0,00 & 140 \\
\hline 1710-19 & 139 & 54,94 & 97 & 38,34 & 17 & 6,72 & 0 & 0,00 & 0 & 0,00 & 253 \\
\hline Recuperación 1670-1719 & 405 & 43,69 & 391 & 41,18 & 121 & 13,05 & 5 & 0,54 & 5 & 0,54 & 927 \\
\hline $1720-29$ & 204 & 51,91 & 158 & 40,20 & 23 & 5,85 & 0 & 0,00 & 8 & 2,04 & 393 \\
\hline $1730-39$ & 145 & 37,66 & 191 & 49,61 & 20 & 5,19 & 2 & 0,52 & 27 & 7,01 & 385 \\
\hline $1740-49$ & 190 & 43,58 & 210 & 48,17 & 34 & 7,80 & 2 & 0,46 & 0 & 0,00 & 436 \\
\hline $1750-59$ & 219 & 54,48 & 164 & 40,80 & 18 & 4,48 & 0 & 0,00 & 1 & 0,25 & 402 \\
\hline $1760-69$ & 322 & 67,93 & 134 & 28,27 & 16 & 3,38 & 0 & 0,00 & 2 & 0,42 & 474 \\
\hline $1770-79$ & 389 & 78,74 & 94 & 19,03 & 11 & 2,23 & 0 & 0,00 & 0 & 0,00 & 494 \\
\hline $1780-89$ & 287 & 65,08 & 148 & 33,56 & 5 & 1,13 & 0 & 0,00 & 1 & 0,23 & 441 \\
\hline 1790-99 & 333 & 64,41 & 170 & 32,88 & 7 & 1,35 & 0 & 0,00 & 7 & 1,35 & 517 \\
\hline Expansión 1720-1799 & 2.089 & 58,98 & 1.269 & 35,83 & 134 & 3,78 & 4 & 0,11 & 46 & 1,30 & 3.542 \\
\hline $1800-09$ & 223 & 60,93 & 142 & 38,80 & 1 & 0,27 & 0 & 0,00 & 0 & 0,00 & 366 \\
\hline 1810-19 & 96 & 82,05 & 21 & 17,95 & 0 & 0,00 & 0 & 0,00 & 0 & 0,00 & 117 \\
\hline $1820-29$ & 183 & 64,66 & 94 & 33,22 & 4 & 1,41 & 2 & 0,71 & 0 & 0,00 & 283 \\
\hline $1830-36$ & 39 & 78,00 & 9 & 18,00 & 2 & 4,00 & 0 & 0,00 & 0 & 0,00 & 50 \\
\hline Decadencia 1800-1836 & 541 & 66,30 & 266 & 32,60 & 7 & 0,86 & 2 & 0,25 & $\mathbf{0}$ & 0,00 & 816 \\
\hline TOTAL & 4.221 & 44,72 & 3.592 & 38,05 & 1.277 & 13,53 & 240 & 2,54 & 109 & 1,15 & 9.439 \\
\hline
\end{tabular}

Fuente: elaboración propia. ACAMSV. Sig. 2.1/1-214 y sig. 2.2.1/2-8.

\footnotetext{
${ }^{9}$ Dentro de este apartado se incluyen los examinados que no encajan en el resto de categorías, fundamentalmente maestros que realizaban un segundo examen,
} como ya se ha indicado, pero también candidatos casados con una hija de maestro, quintados o pobres (a los que la corporación reducía las tasas de examen). 
No obstante, la apertura social que caracterizó a la corporación en el siglo xvi contrasta con el cierre que conoció en el siglo xviı. Este estuvo determinado, en parte, por el brutal incremento que experimentaron las tasas de examen en esta centuria. El aumento más espectacular se produjo en el tránsito secular, ya que entre 1599 y 1604 los derechos exigidos a los oficiales de la tierra casi se quintuplicaron, mientras que los de los forasteros y extranjeros se triplicaron en exceso. En términos reales, el incremento fue algo menor debido al ascenso en un $50 \%$ de los salarios de los peones de la construcción, tomados como referencia. Pero aun así, los días de trabajo requeridos para abonar las tasas pasaron de 12,5 a 40 en el primer caso; de 25 a 60 en el segundo, y de 37,5 a 80 en el tercero. En principio, la elevación de las tasas, como factor endógeno, no obedecía a una estrategia deliberada de la corporación para favorecer a los candidatos emparentados con la élite artesanal, sino que se derivaba de las dificultades financieras que sufría como consecuencia del incremento de la presión fiscal y del elevado coste de los frecuentes pleitos. Sin embargo, al insertarse en un contexto general de deterioro de las condiciones de producción y de mercado de la actividad manufacturera, el incremento de los derechos de examen hacía cada vez menos atractivo el acceso a la élite gremial para los candidatos no emparentados con ella.

El problema se acentuó al intensificarse las dificultades de la corporación. En 1631, esta decidió incrementar un 33\% los derechos de examen de todas las categorías. En 1663, al no autorizarse su petición de elevar su nivel de endeudamiento, se optó por doblar las tasas nuevamente. Pero en esta ocasión la ciudad de Valencia volvió a ejercer un papel moderador, oponiéndose al aumento. Sin embargo, la paralización fue solo temporal, ya que en 1675 se autorizó un incremento general del 50\%; y en 1687, tras los gastos ocasionados por la conversión del gremio en colegio, se efectuó otro aumento de la misma entidad. Como resultado de todo el proceso, entre 1598 y 1687 las tasas se habían incrementado en un 1340\% para los oficiales de la tierra; un $980 \%$ para los forasteros, y un $860 \%$ para los extranjeros, lo que en jornales suponía pasar de 12,5 a 120 días para los primeros; de 25 a 180 días para los segundos, y de 37,5 a 240 días para los terceros. En estas condiciones, era lógico un cierre de la corporación, en la que los hijos de maestros representaban un promedio del 45,56\% de los exámenes realizados en el periodo 1610-1669, mientras que los valencianos suponían el 34,11\%, los forasteros el $17,11 \%$ y los extranjeros el 2,78\%.

Sin embargo, a medida que se fueron superando las dificultades más graves y se sentaron las bases de la recuperación en el último tercio del siglo xvir, la exigencia de unas tasas tan elevadas no constituyó un obstáculo disuasorio insalvable para los candidatos ajenos a la corporación ante las oportunidades ofrecidas en este mercado laboral renovado. Así, a mediados del siglo xvil se aprecia un ligero repunte de los extranjeros, tanto genoveses como franceses, antes de experimentar una clara regresión, ya definitiva a partir de la década de 1660. También la presencia de los forasteros se recupera claramente entre las décadas de 1630 y 1680, aunque inicia luego un cierto retroceso, intensificado tras la guerra de Sucesión. En paralelo, se observa un claro aumento de los candidatos de origen valenciano, que llegan a rondar el $50 \%$ en las décadas de tránsito entre los siglos XVII y XVIII. El resultado combinado de estos procesos es la moderación de la elevada proporción que habían alcanzado los hijos de los maestros a comienzos del siglo xviI, cuando llegaron a superar el 50\% de los exámenes realizados. Su proporción es claramente inferior el resto de la centuria, y desciende incluso del $40 \%$, sobre todo en las décadas de 1680 y 1690, una nueva fase de dinamismo productivo sobre la que se sentaron las bases del esplendor sedero del siglo xviII.

La menor incidencia de las dificultades del siglo xvir en Valencia con respecto a otros centros sederos de la monarquía, unida a la recuperación del último tercio de la centuria, estimuló una nueva corriente migratoria de mano de obra cualificada hacia la ciudad, atraída por las oportunidades laborales que se estaban generando, sin que las elevadas tasas exigidas fueran una barrera infranqueable. La mejor evidencia de lo ventajoso que resultaba el ejercicio de la manufactura de la seda en el mercado laboral valenciano del último tercio de la centuria fue la frecuencia con la que los candidatos estaban dispuestos a abonar elevadas sumas de dinero extra para redimir la práctica como aprendiz u oficial y acceder rápidamente a la élite artesanal. Este mecanismo comenzó a utilizarse de forma sistemática a partir de 1675 (abonando una libra por cada mes de práctica que faltaba para ejercer un año como oficial, duración que se extendió a dos años a partir de las nuevas ordenanzas de 1687). Desde 1679, se permitió redimir también los cinco años de práctica como aprendiz que se necesitaban para matricularse como oficial (a razón de 1,02 libras por mes). Ambos procedimientos fueron utilizados por más del $10 \%$ de los candidatos que efectuaron el examen en las dos últimas décadas del siglo xvir, abonando por ello unos derechos adicionales que rondaron el $50 \%$ del valor de las tasas correspondientes, aunque esta práctica acabó siendo prohibida en las ordenanzas de 1736 (Franch, 2014, pp. 50 y 56$)^{10}$.

La mejora de las condiciones de la manufactura de la seda valenciana desde mediados del siglo xvi dio lugar a que el proceso de cierre que había iniciado la corporación a principios de la centuria se invirtiera temporalmente. La tendencia a la baja de los extranjeros y forasteros se invirtió en dicho periodo, mientras que los oficiales de la tierra llegaron a superar la proporción que representaban los hijos de los maestros en el tránsito secular. Fue tras la guerra de Sucesión cuando se reanudó la tendencia hacia el cierre de la corporación, que adquirió un carácter abrumador a partir de mediados de siglo. A ello contribuyó un nuevo incremento (el último) de las tasas de examen. Pero, como en la centuria anterior, la causa de su elevación fue las dificultades financieras de la corporación y no una voluntad expresa de excluir a los candidatos ajenos al gremio. El incremento fue, de nuevo, de un 50\%, lo que agudizó la discriminación entre los candidatos forasteros y extranjeros, que se vieron obligados a satisfacer una cantidad equivalente al salario de 270 y 360 días de trabajo, respectivamente.

En estas condiciones, se comprende que los candidatos de origen extranjero tendiesen a desaparecer y que los forasteros no volviesen a alcanzar el 10\%, llegando incluso a bajar del $2 \%$ a partir de la década de 1780 . La sedería valenciana se nutrió básicamente durante su periodo de mayor esplendor de mano de obra cualificada de origen autóctono. Los oficiales de la tierra aún representaron una proporción superior al 40\% hasta la década de 1760 . Pero, a partir de entonces, tendieron a

\footnotetext{
10 Esta práctica no era completamente nueva, ya que durante el siglo xvı, el otro periodo de dinamismo de la corporación, también se produjeron algunas redenciones de periodos formativos.
} 
situarse por debajo del $33 \%$. Fueron realmente los hijos de los maestros los que constituyeron el contingente más importante de la nueva élite artesanal. En las décadas de 1710 y 1720 representaron más del $50 \%$ de los examinados. Posteriormente, retrocedieron ligeramente en favor de los oficiales valencianos, aunque su hegemonía adquirió un carácter cada vez más abrumador desde mediados de siglo. Así, alcanzaron el $66,13 \%$ para el periodo $1750-1800$ y superaron el $70 \%$ durante el siglo XIX.

No obstante, el contexto de los dos periodos aludidos era muy distinto. En la fase de despegue, de mediados de la década de 1710 a la de 1720 , su afluencia estuvo estimulada por las oportunidades laborales y de negocio existentes en la manufactura de la seda, lo que dio lugar a que se alcanzasen entonces las tasas de reproducción artesanal más elevadas de la centuria, tanto en lo relativo al número de maestros como al de los exámenes realizados. Resulta significativo que fuese también entonces cuando algunos maestros recurrieron a un segundo examen con el fin de ampliar las modalidades de los géneros que estaban autorizados a elaborar (como ya había sucedido en el primer cuarto del siglo xvI). Este dinamismo alimentó un mercado laboral todavía abierto, que en parte se nutría de candidatos llegados a la ciudad desde otras poblaciones del reino (Franch, 2014, pp. 60-63).

En este momento, las oportunidades de éxito profesional eran claramente superiores a las de la segunda mitad de la centuria. Las dificultades que experimentó la manufactura de la seda en este último periodo pudieron desestimular a muchos candidatos (especialmente a los forasteros y extranjeros), cada vez menos dispuestos a abonar las elevadas tasas que se les exigían para ejercer una industria que manifestaba síntomas de estancamiento. El fuerte incremento del número de maestros y el cierre de la corporación en torno a los hijos de estos a partir de 1750 evidencia los desequilibrios internos que se estaban consolidando en la corporación, cuya población gremial no paró de crecer, pese a que el número de telares existentes se mantuvo invariable. La consecuencia fue la precarización laboral de muchos de estos nuevos maestros, dependientes de una minoría empresarial (Muñoz, 2014). Por tanto, más que la elevada entidad de las tasas exigidas, fue el deterioro del contexto en el que se desarrollaba el sector lo que explica la constante tendencia hacia el cierre de la corporación que se produjo a partir de 1760 . Una situación agudizada por la coyuntura política y económica de la monarquía y la falta de innovaciones productivas en el seno de una corporación que fue languideciendo hasta el decreto definitivo de supresión de los gremios de 1836.

\section{Conclusiones}

Entre 1450 y 1800 la industria sedera europea vivió grandes transformaciones, en un contexto cada vez más globalizado y competitivo en el que la flexibilidad y capacidad de adaptación de las corporaciones gremiales era un rasgo común. Un proceso acumulativo en el que la introducción puntual de pequeñas innovaciones respondía bien a «the unintended outcome of craftsmen going about their normal business» (Epstein y Prak, 2008 , p. 18), o bien a las iniciativas adoptadas por los empresarios que controlaban cada vez más su actividad, por lo que resulta imprescindible ubicar estas decisiones en su contexto.

El gremio de velluters de Valencia se caracterizó también por su flexibilidad durante toda su existencia, aunque ello no significa que siempre fuera una corporación abierta (al cambio tecnológico o al acceso de personas ajenas al oficio). El mercado laboral del que procedía la élite sedera fluctuó en función de la coyuntura (factores exógenos), sin que la entidad de las tasas de examen (factor endógeno) fuera una barrera infranqueable en contextos expansivos, como la primera mitad del siglo xvi o el tránsito entre los siglos XVII-XVIII. No obstante, la presencia de extranjeros o forasteros fue retrocediendo en favor de una inmigración cercana y, especialmente, del auge de los hijos de maestros, lo que marcó una tendencia al cierre social y geográfico que se agudizó en la segunda mitad del xviI. La introducción de innovaciones (cambios organizativos o productivos motivados por el mercado) evidencia el carácter maleable de la corporación, que desde luego no fue inmóvil y trató de defender los intereses de sus miembros por vías diversas, entre ellas la judicial. El fomento político del sector y el reforzamiento de las prerrogativas del colegio tras la guerra de Sucesión marcaron la evolución de esta industria a finales de la Edad Moderna. Su defensa de un modelo productivo tradicional coincide paradójicamente con el momento de máximo esplendor de la manufactura sedera valenciana. Una situación que se explica por el elemento diferencial que supone tener un acceso privilegiado al mercado colonial.

Si contrastamos la evolución valenciana con la de otros centros sederos mediterráneos, como Lyon o Venecia, podemos observar la diversidad del sistema gremial europeo y el proceso constante de adaptación al mercado, aunque con resultados dispares. Si para Lyon la innovación y modernización productiva según las nuevas modas fue un ejemplo exitoso a escala internacional, basado en una nueva forma de producir dentro del gremio (Pérez, 2008), el caso veneciano muestra un contrapunto evidente al reorientar su producción hacia los tejidos de lujo para tratar de hacer frente a la creciente competencia internacional, aunque sin poder evitar el declive definitivo de esta industria (Trivellato, 2008). Por su parte, la sedería valenciana se desarrolló en su etapa de mayor esplendor gracias al impulso de una burguesía autóctona emergida de la élite artesanal, y orientando básicamente su producción hacia el mercado americano. No obstante, la emancipación de las colonias y el inestable contexto político español de la primera mitad del siglo xIx, unido al tradicionalismo productivo y la menor competitividad de las sedas valencianas frente a los géneros de origen francés y asiático, marcaron el inicio de una crisis irreversible, en la que el gremio ya poco pudo hacer.

\section{Agradecimientos}

Los autores expresan su agradecimiento al doctor Luis M. Rosado Calatayud por su valiosa colaboración en el análisis de la documentación y la elaboración de la base de datos en la que se basa este artículo. Asimismo, las sugerencias realizadas por los evaluadores anónimos han permitido mejorar la versión inicial del estudio llevado a cabo. El presente trabajo se inserta en el marco del proyecto «Privilegio, trabajo y conflictividad. La sociedad moderna de los territorios hispánicos del Mediterráneo occidental entre el cambio y las resistencias» (PGC2018-094150-B-C21), financiado por el Ministerio de Ciencia e Innovación y la Agencia Estatal de Investigación. 


\section{Bibliografía}

Aranda, F. J. (2017). «El horizonte de la seda en el Reino de Toledo en la época moderna». En: Franch, R. y Navarro, G. (eds.), Las rutas de la seda en la historia de España y Portugal. Valencia: PUV, pp. 163185.

Caracausi, A., Davies, M. y Mocarelli, L. (eds.) (2018). Between Regulation and Freedom. Work and Manufactures in European Cities, 14th18th Centuries. Newcastle upon Tyne: Cambridge Scholars Publishing.

Casado, H. (2004). «Guilds, Technical Progress and Economic Development in Preindustrial Spain", en Massa, P. y Moioli, A. (eds.), Dalla corporazione al mutuo soccorso. Organizzazione del lavoro tra XVI e Xx secolo. Milano: Franco Angeli, pp. 309-327.

Davis, K. y De Munck, B. (eds.) (2014). Innovation and Creativity in Late Medieval and Early Modern European Cities. Surrey: Ashgate.

De Munck, B. (2007). Technologies of learning. Apprenticeship in Antwerp guilds from the 15th century to the end of the ancien regime. Brepols: Turnhout.

De Munck, B. (2011). «Gilding golden ages: perspectives from early modern Antwerp on the guild debate, c. 1450-c. 1650», European Review of Economic History, 15, 221-253.

De Vries, J. (1987). La urbanización de Europa 1500-1800. Barcelona: Crítica.

Epstein, S. R. y Prak, M. (eds.) (2008). Guilds, innovation and the European economy, 1400-1800. Cambridge: Cambridge University Press.

Epstein, S. R. (1998). «Craft guilds, apprenticeship, and technological change in preindustrial Europe», The Journal of Economic History, 58 (3), 684-713.

Farr, J. R. (2000). Artisans in Europe, 1300-1914. Cambridge: Cambridge University Press.

Fortea, J. I. (2009). «Ciudad y fenómeno urbano en la España de la Ilustración", en Fernández, C. et al. (eds.), El mundo urbano en el siglo de la Ilustración. Santiago de Compostela: Xunta de Galicia, vol. 1, pp. 59-93.

Franch, R. (1999). «La evolución de la sedería valenciana durante el reinado de Felipe II», en Belenguer, E. (ed.), Felipe II y el Mediterráneo. Sociedad Estatal para la Conmemoración de los Centenarios de Felipe II y Carlos V. Madrid, vol. 1, pp. 289-310.

Franch, R. (2000). La sedería valenciana y el reformismo borbónico. Valencia: Institució Alfons el Magnànim.

Franch, R. (2004). «El artesanado sedero valenciano en el siglo xvII», en Aranda, F. J. (coord.), La declinación de la Monarquía Hispánica. Cuenca: UCLM, pp. 511-524.

Franch, R. (2014). «Los maestros del colegio del arte mayor de la seda de Valencia en una fase de crecimiento manufacturero (16861755)», Hispania, 246 (74), 41-68.

Franch, R., Muñoz, D. y Rosado, L. (2016). «La reproducción de los maestros y la transformación de las condiciones sociales de los miembros del Colegio del Arte Mayor de la Seda de Valencia en el siglo xVIII", Revista de Historia Industrial, 65 (3), 15-49.

Franch, R., Muñoz y D. y Rosado, L. (2018). «El gremio de «velluters» de Valencia en el siglo xvir: las estrategias adoptadas antes la crisis financiera de la corporación y las fluctuaciones del mercado de trabajo", en Amelang, J. et al. (coords.), Palacios, plazas y patíbulos. La sociedad española moderna entre el cambio y las resistencias. Valencia: Tirant, pp. 109-124.

Franch, R., Muñoz, D. y Rosado, L. (2019). «El gremio de velluters de Valencia, 1479-1600. La apertura del mercado laboral como factor de dinamismo", en Solà, Â. (ed.), Artesanos, gremios y géneros en el sur de Europa (siglos XVI-XIX). Barcelona: Icaria, pp. 101-126.

García Cárcel, R. (1975). Las germanías de Valencia. Barcelona: Península.
Hamilton, E. J. (1975). El tesoro americano y la revolución de los precios en España: 1501-1650. Barcelona: Ariel.

Hernández, R. y González, J. D. (2015). «Gremios y corporaciones laborales. Debates historiográficos y estado de la cuestión». Áreas. Revista Internacional de Ciencias Sociales, 34, 7-18.

Igual, D. (1998). Valencia e Italia en el siglo xv. Rutas, mercados y hombres de negocios en el espacio económico del Mediterráneo Occidental. Valencia: Bancaixa.

López, V. y Nieto, J. A. (eds.) (1996). El trabajo en la encrucijada. Artesanos urbanos de la Europa de la Edad Moderna. Madrid: Libros de la Catarata.

Lucassen, J., De Moor, T. y Van Zanden, J. (eds.) (2009). «The Return of the Guilds", International Review of Social History, Supplements, 16

Mocarelli, L. y Ongaro, G. (2019). Work in Early Modern Italy, 1500-1800. Cham: Palgrave Macmillan.

Muñoz, D. (2014). «El artesanado sedero valenciano a finales del Antiguo Régimen: crisis sedera, proletarización social y declive progresivo del colegio del arte mayor de la seda de Valencia (17591836)», en Franch, R. et al. (coords.), Cambios y resistencias sociales en la Edad Moderna. Madrid: Sílex, pp. 85-96.

Muñoz, D. (2015). “"Per camins inussitats i sendes molt apartades”. Contrabando de seda valenciana hacia Castilla durante la segunda mitad del siglo xvI», Revista de Historia Moderna, 90, 113-132.

Muñoz, D. (2017). «La seda en el comercio colonial español durante la segunda mitad del siglo xviII», en Franch, R. y Navarro, G. (eds.), Las rutas de la seda en la historia de España y Portugal. Valencia: PUV, pp. 275-311.

Navarro Espinach, G. (1999). Los orígenes de la sedería de Valencia. Valencia: Ayuntamiento de Valencia.

Nieto, J. A. (2013). «El acceso al trabajo corporativo en el Madrid del siglo xviII: una propuesta de análisis de las cartas de examen gremial», Investigaciones de Historia Económica, 9, 97-107.

Nieto, J. A. y Zofío, J. C. (2015). «Los gremios de Madrid durante la Edad Moderna: una revisión». Áreas. Revista Internacional de Ciencias Sociales, 34, 47-61.

Ogilvie, S. C. (2008). «Rehabilitating the guilds: a reply», The Economic History Review, 61 (1), 175-182.

Ogilvie, S. C. (2019). The European guilds: an economic analysis. Princeton: Princeton University Press.

Palop, J. M. (1977). Fluctuaciones de precios y abastecimiento en la Valencia del siglo XVIII. Valencia: Institució Alfons el Magnànim.

Pérez, L. (2008). «Inventing in a world of guilds: silk fabrics in Eighteenth century Lyon", en Epstein, S. R. y Prak, M. (eds.), Guilds, innovation and the European economy, 1400-1800. Cambridge: Cambridge University Press, pp. 232-263.

Pérez García, P. (2017). Las germanías de Valencia, en miniatura y al fresco. Valencia: Tirant.

Prak, M. y Wallis, P. (2020). Apprenticeship in Early Modern Europe. Cambridge: Cambridge University Press.

Prak, M., Crowston, C. H., De Munck, B., Kissane, C., Minns, C., Schalk, R. y Wallis, P. (2020). "Access to trade: monopoly and mobility in European craft guilds in the Seventeenth and Eighteenth centuries», Journal of Social History, 54 (2), 421-452.

Solà, À. y Yamamichi, Y. (2015). «Del aprendizaje a la maestría. El caso del gremio de velers de Barcelona, 1770-1834», Áreas. Revista Internacional de Ciencias Sociales, 34, 77-91.

Stabel, P. (2004). «Guilds in late medieval Flanders: myths and realities of guild life in an export-oriented environment», Journal of Medieval History, 30, 187-212.

Trivellato, F. (2008). "Guilds, technology, and economic change in Early Modern Venice», en Epstein, S. R. y Prak, M. (eds.), Guilds, innovation and the European economy, 1400-1800. Cambridge: Cambridge University Press, pp. 199-231. 